\title{
Physiological Effects of Blue Pulsed LED in an Indoor Lighting Environment
}

\author{
Efectos Fisiológicos de Luz LED Azul Intermitente en un Ambiente de Iluminación en Interiores
}

\author{
C. A. Chaveznava-Treviño ${ }^{1,2}$, T. Katsuura², Y. Shimomura² \\ 'Universidad de Monterrey \\ ${ }^{2}$ Chiba University
}

\begin{abstract}
Purpose: An experiment was conducted to investigate the physiological effects of a continuous blue pulsed light emitting diode (BP-LED) added to a task lamp in an actual indoor lighting environment and its influence in alertness having as a final purpose to develop a commercial product that could be applied in situations similar to those depicted in the present work. Design methodology: Previous research studies have stated that the addition of pulsed light evokes physiological changes that may induce alertness. The participants were exposed to four different lighting conditions. Electroencephalograms (EEG), pupil sizes, heart rates (HR), performance tests, and subjective reactions were measured. Findings: Low colour temperature light and the BP-LED revealed an improved alertness according to the data from the EEG recordings. The intervention of the BP-LED in a high colour temperature ambiance was beneficial in maintaining high levels of alertness compared to the conditions where the BP-LED was not used. It was tested that the use of a BP-LED in a task lamp may be beneficial in improving or maintaining alertness levels in an indoor workplace ambiance. Originality and Value: Designing of an adequate workplace task lamp light that improves alertness for in-house, office, or classroom situations in which it is essential.
\end{abstract}

KEYWORDS: blue pulsed LED; flickering; alertness; physiological effects; work lighting environment; workplace design 


\section{RESUMEN}

Propósito: Un experimento fue llevado a cabo para investigar los efectos fisiológicos que una luz azul LED pulsada de manera intermitente (BP-LED), adicionada a una lámpara de escritorio, y en un ambiente interior; pueda influir en el estado de alerta de una persona con la finalidad de desarrollar un producto comercial que pueda ser aplicado para los casos desarrollados y otros posibles escenarios. Metodología de Diseño: En estudios anteriores se establece que la adición de luz en pulsaciones evoca cambios fisiológicos que pueden inducir al estado de alerta. Los participantes experimentaron cuatro escenarios de iluminación. Se registraron mediciones con respecto a encefalografía (EEG), tamaño pupilar, ritmo cardiaco, prueba de performance, así como evaluación subjetiva. Hallazgos: Los datos de EEG revelaron un mayor estado de alerta durante la exposición a iluminación cálida aunado a luz BP-LED. La intervención de luz fría y BP-LED denotó ser benéfica en el nivel de estado de alerta en comparación con las condiciones donde el BP-LED no intervino. Se logró evaluar que el uso de BP-LED en una lámpara de escritorio puede ser benéfico para mejorar o mantener el estado de alerta cuando sea usado en un espacio interior. Originalidad y Valor: Propuesta para diseñar una luminaria de escritorio; para uso casero, laboral o de estudio; que mejore el estado de alerta de las personas

PALABRAS CLAVE: luz azul LED; intermitencia; estado de alerta; efectos fisiológicos; iluminación del espacio de trabajo; diseño del espacio de trabajo

\section{Correspondencia}

DESTINATARIO: Carlos Alberto Chaveznava Treviño INSTITUCIÓN: Centro Roberto Garza Sada (CRGS), Departamento de Diseño Industrial, Universidad de Monterrey

DIRECCIÓN: Av. Morones Prieto \#4500 Poniente, Col. Jesús M. Garza, C. P. 66238, San Pedro Garza García, Nuevo León, México CORREO ELECTRÓNICO: carlos.chaveznava@udem.edu

\section{Fecha de recepción:}

11 de agosto de 2017

Fecha de aceptación:

4 de septiembre de 2018 


\section{INTRODUCTION}

Humans are diurnal creatures by nature and their physiological functions depend on the day-night cycle ${ }^{[1]}$. However, since the introduction of artificial light in the living environments, humans have been exposed to new lighting ambiances that are different compared to the natural daylight ${ }^{[2]}$. Several studies have been conducted regarding human behaviour under various lighting environments, most of them being under controlled situations or in opposite scenarios (morning-afternoon, day-night, dim-bright); consequently, clear data about the differences or the effects of lighting conditions on the human behaviour have been obtained.

However, these data do not describe the physiological responses when exposed to artificial lighting environments such as those at the office, hospitals, schools or those when affected by shifts at work or by long journals of work ${ }^{[3][4]}{ }^{[5]}$. Therefore, the importance of maintaining the state of alertness in humans, in order to assure a good response when assertive responses at work are needed.

With the introduction of the LED lighting for commercial use, new challenges in regulating its uses and applications have arisen ${ }^{[6]}{ }^{[7]}$, along with the physiological effects it may have upon human interaction ${ }^{[8]}$.

Standards are written to state the average or recommended light conditions for certain activities ${ }^{[9]}{ }^{[10]}$ but nowadays with the new technologies in LED lighting, the possibility of having ambiances with simulated day light has become a close reality, and not too much has been researched about the effects of LED light in a workplace scenario [5] [11] [12] [13].

Adequate illumination with the appropriate spectrum of light in our environment should be a concern for most of the employers, hospitals, offices, schools or any place that has people developing an activity indoors during the day, this is because of the effects that the lack of daylight can cause in humans; starting with minor effects such as headaches or eye strain, and up to the level of changing the natural synchrony of our circadian rhythm ${ }^{[14][15][16][17]}$.

It has been reported that certain optical radiations at certain wavelengths emitted by LED light has specific physiological effects even in the case of monochromatic light, which affects alertness or the circadian rhythm [4] [18] [19] [20], among other effects. These physiological effects depend on the way the LED is applied: either by a steady exposure, short interrupted periods

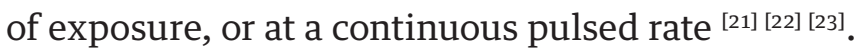

There are studies that reports physiological changes upon addition of pulsed light at frequencies not visible to the human eye, either by single pulses or by a train of continuous pulses during spaced lapses of time, but all of them during absence of any other lighting in the ambiance, implying the improvement on alertness levels ${ }^{[21][24]}$.

In the present experiment we are applying a continuous stream of pulses (flickering) that give a sensation of low intensity of light (dimming effect), along with different light scenarios; therefore, the present study has the value that it was tested as a real life condition and with a flickering light rather than a continuous lighting or a time elapsed pulsed type.

The use of a dimmed LED light superimposed to a task lamp was decided to comply with the references that even with small amounts of blue light, physiological changes can be perceived [21] [24]. Also, dimming light may reduce the subjective perception of working in a blueish ambiance which may affect qualitative perception; and finally, dimming a LED light will not affect the irradiance emitted and will reduce power consumption turning into an economical benefit for the facilities who may use it. 
EEG has been related to alertness in different studies, either by outputs of mental fatigue (increased power in frontal theta $(\theta)$ and parietal alpha $(\alpha)$ under a sustained numerical test process); also by the exposure to short and long-wavelength light during the morning (470 $\mathrm{nm}$ and $630 \mathrm{~nm}$ ); or by the association of cognitive functional decrements over time when performing a simulated air traffic control task for up to two hours ${ }^{[25]}[26][27]$.

Exposure to blue LED during day time has been proven to boost alertness, mood, and reaction times more significantly than the green or red LED light ${ }^{[28][29]}$ [30][31]. This is because the intrinsically photosensitive retinal ganglion cells ${ }^{[32]}$ in the photoreceptors are more sensitive to blue light radiation. The Blue LED light has also been proved to cause changes in the circadian rhythm even at low levels of illuminance [33] [34] [35] [36].

Another method to introduce blue light in the human system involves supplying it in pulses or short amounts of exposure. Experiments have revealed that a pulsed exposure shows the same effects as that when exposed to a continuous stream of light [24] [37]

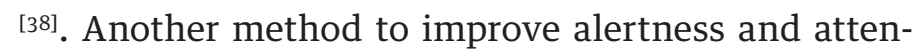
tion levels with low intensity levels or very short doses of light using time programmed pulses has been developed [39] [40].

However, the possibility of exposure of ordinary people to intermittent short exposures on a normal day is currently limited as, so far, currently there is no effective technology to improve the state of alertness for people at work under closed and artificially illuminated spaces.

Consequently our development can help to achieved this by using a flickering controller device that can provide a dimmed blue light exposure to the user and provide the needed improvement at work when it is required.
In case of a flickering light, whether it will be perceived by the human eye or not depends on the frequency and the condition of the luminaire. If the flickering is not controlled properly, it may affect those susceptible to epilepsy ${ }^{[41]}[42][43]$.

On a workday, a person generally prepares to start the day in the office few minutes in advance before being directly exposed to the desk, ceiling, and computer lights. This exposure to artificial light does not necessarily mean that the body will react in a positive manner. Furthermore, in case of a change in the light scenarios in the real world, alertness can be affected differently. Hence, we simulated in an experimental room to resemble a typical workplace with an artificial light environment and no natural day light intervention, in our case it was focused to clerical work as that performed in offices, schools or hospitals; considering that we are not analysing the factor of tiredness and circadian rhythm deviation due to shifts at work or long journals of like nurses and Doctors have.

The whole project obeys to a main hypothesis regarding that BP-LED technology can provide an effective (cost/benefit) solution in order to improve the current artificial lighting techniques nowadays used in closed spaces such as offices, hospitals, schools, etc. As for this experiment or part of the whole process of design of this new device, we aim to test the hypothesis that BP-LED blue-pulsed illumination superimposed on ambient lighting generated by BP-LED technology evokes a greater degree of alertness in subjects under observation under experimental design conditions.

An alternative was then hypothesized that "By the addition of the BP-LED in a task lamp, the measures will not make effect in alertness levels".

That, in order to understand the physiological effects on the humans in an artificial light environment by simulating a typical time at work with no daylight con- 
tributions with the end objective, as we mentioned; of developing a commercially available controller that can be added or superimposed to task lamps to provide support when cognitive effort is required.

Therefore we developed a research question as a guide to test and support the hypothesis and to perform the experiment (please refer to "Procedures" section):

To measure changes in EEG activity to estimate the impact factor in alertness under the different light colour temperature's task light and BP-LED interventions. As it is assumed work load across time (and stages) of the test will affect alertness; and considering also the presumption that the interaction of light colour temperature (LCT) and BP-LED will affect alertness.

\section{MATERIALS AND METHODS}

For this experiment, 14 participants volunteered: 7 males and 7 females with an average age of 26 years (range 22-35) and a standard deviation (SD) of \pm 4 years. They all had normal or corrected to normal vision, an average weight of $61.3 \mathrm{~kg}$ (range 50-80) with an SD of $\pm 11.3 \mathrm{~kg}$, and an average height of $1.65 \mathrm{~m}$ (range 1.55-1.79) with an SD of $\pm 0.08 \mathrm{~m}$.

All the participants were informed about the procedures and they were made to sign the informed consent according to the Ethics Committee of Chiba University, in Japan, where the experiment took place.

A small sample size was selected because of the type of study performed. There are different types of experiments, those related to test a formal hypothesis or those based on a yes or no testing of a desired goal. In this study it was based on testing a hypothesis related to a physiological response, it was considered then as a continuous variable type to be measured.

In defining the size to measure a continuous variable, with a single group of individuals and by a multiple crossover with repeated measures type of study, it is needed to measure the variables as a before and after effect of each treatment for each individual, there is no control group, as each subject is his/her own control; therefore the effect of subject to subject variation is eliminated. This type of design was used to eliminate interindividual variability.

The age group was selected in a close range (20`s and 30 s) to avoid significant differences in the EEG readings when exposed to the different light conditions as previous studies have demonstrated that age reduces the effects of light on brain functions ${ }^{[44]}[45]$ [46].

Experiments like this have a significant value due to the objective type of results that are obtained; as all measurements are actual changes in physiological responses; furthermore a qualitative analysis was included for consistency review.

\section{Lighting conditions and ambiance}

The experiment was conducted under four different lighting conditions and it was held in an experimental room that was fitted as a simulated office (Table 1).

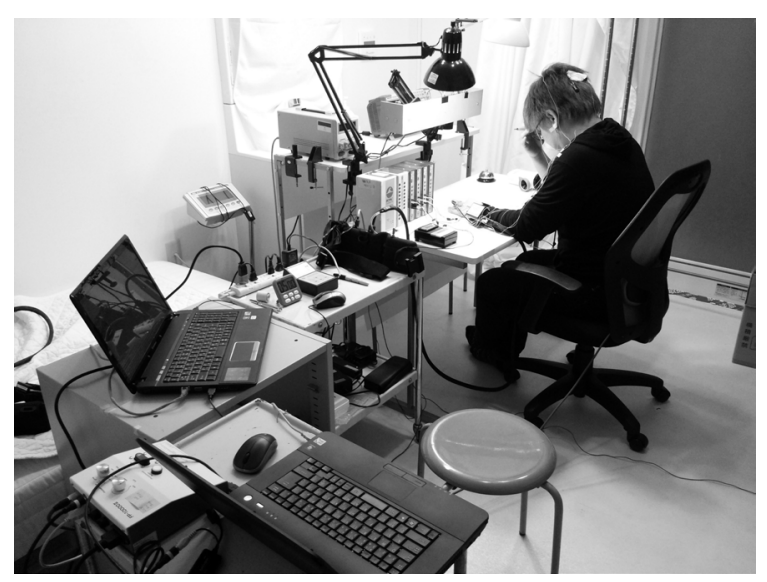

FIGURE 1. Office mockup.

The room had a desk, an adjustable office chair with armrest, an air conditioner unit in the wall behind the participant; no windows, and three doors which were kept closed to avoid any noise or outside light contri- 
TABLE 1. Lighting conditions.

\begin{tabular}{|c|c|c|c|c|}
\hline & Condition "A" & Condition "B" & Condition "C" & Condition "D" \\
\hline Ceiling light & $3000 \mathrm{~K}$ & $3000 \mathrm{~K}$ & $3000 \mathrm{~K}$ & $3000 \mathrm{~K}$ \\
\hline Eye level & $6201 x$ & $6201 \mathrm{x}$ & $6201 \mathrm{x}$ & $6201 \mathrm{x}$ \\
\hline Task Lamp & $2700 \mathrm{~K}$ & $2700 \mathrm{~K}$ & $6500 \mathrm{~K}$ & $6500 \mathrm{~K}$ \\
\hline Eye level & $7001 x$ & $7001 x$ & $7001 x$ & 700 lx \\
\hline Combined & $13201 \mathrm{x}$ & $1320 \mathrm{~lx}$ & $1320 \mathrm{~lx}$ & $13201 \mathrm{x}$ \\
\hline $\begin{array}{l}\text { Blue Pulsed LED @ } 100 \\
\text { Hz flickering rate (1 ms } \\
\text { for 'on' state and } 9 \mathrm{~ms} \\
\text { for 'off' state) }\end{array}$ & & $\begin{array}{c}\text { BP-LED@ Irradiance } \\
\text { of } 15 \mu \mathrm{W} / \mathrm{cm}^{2}\end{array}$ & & $\begin{array}{c}\text { BP-LED@ Irradiance } \\
\text { of } 15 \mu \mathrm{W} / \mathrm{cm}^{2}\end{array}$ \\
\hline
\end{tabular}

bution (Figure 1); with the intention to simulate an office ambiance and at the same time a clerical type of work with time limitation as a performance test to maintain a steady level of activity. There were no computers involved in the participant's intervention, hence no additional screen lights were influencing the test (Figures 2 and 3).

The experiment was conducted between 10:00 a.m. and 12:00 p.m. The temperature was maintained at 21 ${ }^{\circ} \mathrm{C}$ with an SD of $\pm 1.6^{\circ} \mathrm{C}$ and was controlled using a typical mini split-system air-conditioner.

The room had a ceiling lighting with eight units of E26 type bulbs of $60 \mathrm{~W}, 0.19 \mathrm{~A}$, and $695 \mathrm{~lm}$, which after combining with the task lamp lights had an average of $1320 l x$ and an SD of $\pm 58 l x$. The task lamps used 2 LEDs: one LED with $6.5 \mathrm{~W}, 65 \mathrm{~mA}, 420 \mathrm{~lm}$, E26 socket type for $2700 \mathrm{~K}$ colour temperature (“A" and "B"), and the other LED with $8 \mathrm{~W}, 80 \mathrm{~mA}, 720 \mathrm{~lm}$, E26 socket type for the $6500 \mathrm{~K}$ colour temperature ("C" and " $\mathrm{D}$ ").

To avoid disability and discomfort glare during the execution of the test, light sources were set outside the $45^{\circ}$ 'forbidden angle' for the task lamp and the ceiling lights. Surface on desk was covered with a white bond paper (reflectance value of $75 \%$ ).

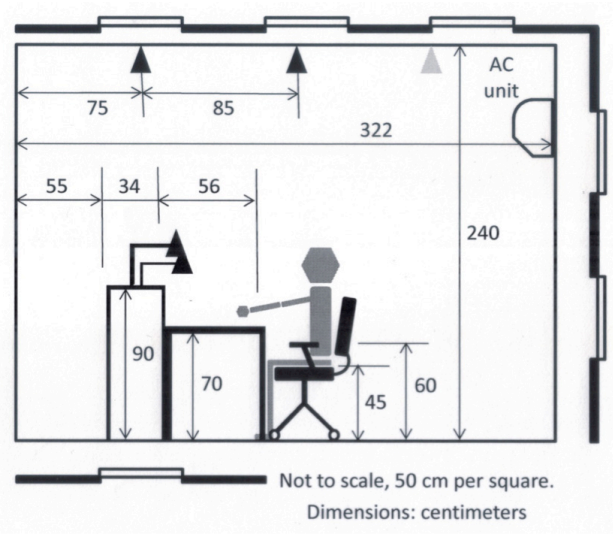

FIGURE 2. Office mockup elevation.

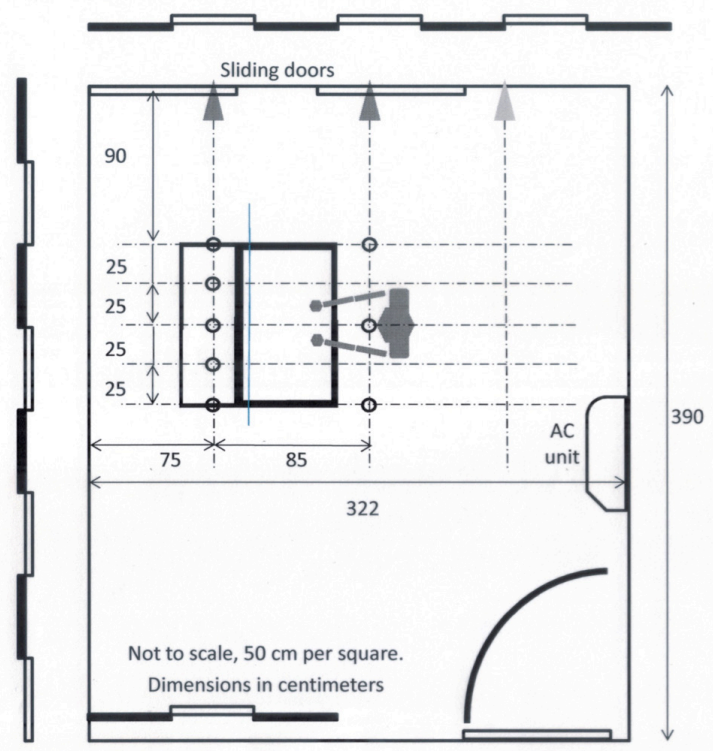

FIGURE 3. Ceiling plan light distribution. 
TABLE 2. Reflectance and luminance values.

\begin{tabular}{|c|c|c|c|c|c|c|c|c|c|c|}
\hline \multicolumn{11}{|c|}{ Reflectance and luminance values (lux) } \\
\hline & \multicolumn{2}{|c|}{$\begin{array}{l}\text { Desk } \\
\text { surface }\end{array}$} & \multicolumn{2}{|c|}{$\begin{array}{l}\text { Eye } \\
\text { Level }\end{array}$} & \multicolumn{2}{|c|}{$\begin{array}{c}\text { Vertical } \\
\text { Reflectance }\end{array}$} & \multicolumn{2}{|c|}{$\begin{array}{c}\text { Refraction } \\
\text { Angle Reflectance }\end{array}$} & \multirow[t]{2}{*}{$\begin{array}{l}\text { Uniformity } \\
\text { Ratio }\end{array}$} & \multirow[t]{2}{*}{$\begin{array}{l}\text { Deversity } \\
\text { Radio }\end{array}$} \\
\hline & MEAN & STD. DEV. & MEAN & STD. DEV. & MEAN & STD. DEV. & MEAN & STD. DEV. & & \\
\hline $\begin{array}{l}\text { Ceiling } \\
\text { lights only }\end{array}$ & 617 & 10.8 & 427 & 59.9 & 790 & 1.5 & 337 & 1.2 & 0.99 & 1 \\
\hline $\begin{array}{l}\text { Task } 6500 \\
\mathrm{~K}+\text { Ceiling }\end{array}$ & 618 & 12.1 & 427 & 61.7 & 793 & 2.1 & 339 & 2.08 & 0.99 & 1 \\
\hline $\begin{array}{l}\text { Task } 2700 \\
\mathrm{~K}+\text { Ceiling }\end{array}$ & 615 & 9.15 & 427 & 59.2 & 1023 & 5.68 & 630 & 2.64 & 0.99 & 1 \\
\hline
\end{tabular}

Light reflectance values were measured at desk level, and at the refraction incidence angle of the task lamp light beam (Table 2) in respect to the participant's eye position; in addition, uniformity and diversity ratios were calculated to verify evenness of light in the task surface (Table 2), Illuminance levels were measured at the eye position.

Figure 4 represents the ceiling fixture arrangement; Figure 5, the ceiling luminous intensity distribution and Figure 6, task light and BP-LED locations and luminous light distribution.

The task lamp had an additional Blue LED which was set at $100 \mathrm{~Hz}$ flickering rate ( $1 \mathrm{~ms}$ for 'on' state and 9 $m s$ for 'off' state) and at an irradiance of Irradiance of $15 \mu \mathrm{W} / \mathrm{cm}^{2}$. The Blue LED spectral power distribution (SPD) is shown in Table 3 and Figure 7.

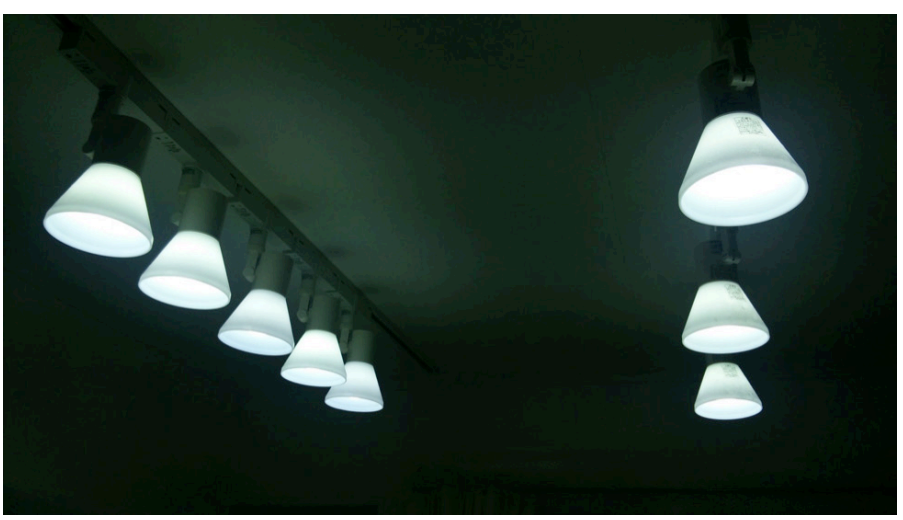

FIGURE 4. Ceiling light fixture arrangement.

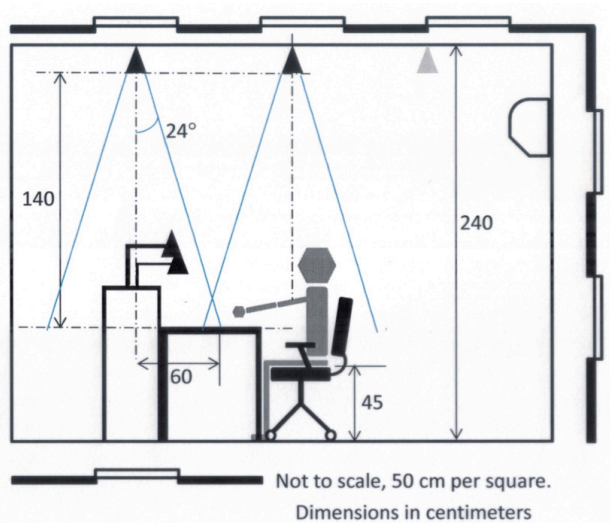

FIGURE 5. Ceiling luminous intensity distribution.

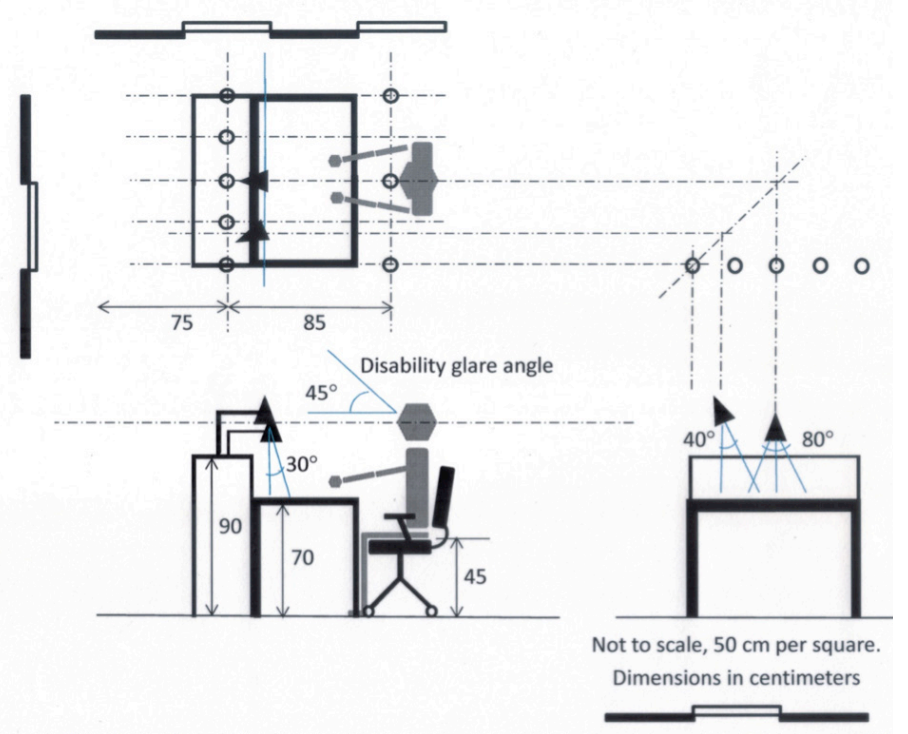

FIGURE 6. Task light and BP-LED locations and luminous distribution. 


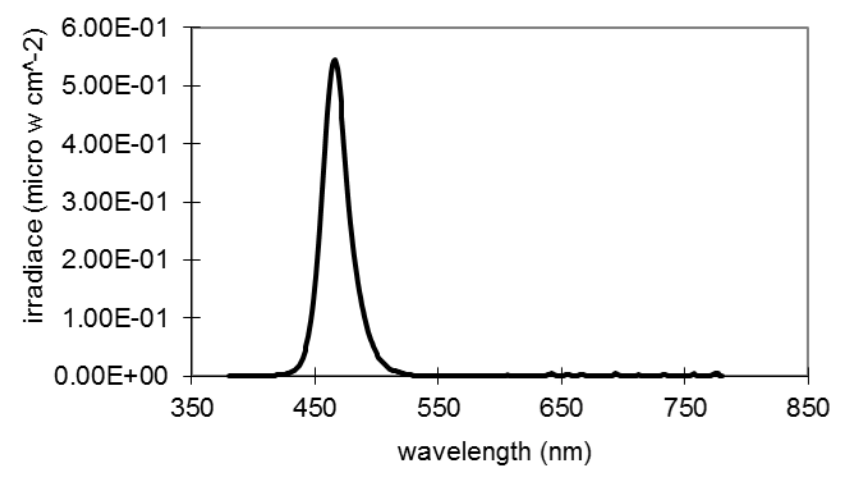

FIGURE 7. Blue LED, Spectral Power Distribution (SPD).

TABLE 3. Blue LED Spectral Power Distribution.

\begin{tabular}{|c|c|c|c|}
\hline \multicolumn{4}{|c|}{ Blue LED Spectral Power Distribution } \\
\hline Irradiance & $\begin{array}{l}\text { Photon } \\
\text { density }\end{array}$ & $\begin{array}{l}\text { Photopic } \\
\text { illuminance }\end{array}$ & $\begin{array}{l}\text { Scotopic } \\
\text { illuminance }\end{array}$ \\
\hline $\begin{array}{c}10^{-6} \\
\mu W / \mathrm{cm}^{2}\end{array}$ & $\begin{array}{c}10^{12} \\
\text { photons } / \mathrm{cm}^{2} / \mathrm{seg}\end{array}$ & $l x$ & $l x$ \\
\hline 15.6 & 37 & 11 & 172 \\
\hline
\end{tabular}

\section{Measurements}

A performance test was applied during the lighting exposures. The participants' performance was evaluated using a numerical test that had to be accomplished within $5 \mathrm{~min}$. The test consisted of 250 randomly generated numbers (ranging from 0-10) and was generated by using the MS Excel 2010 plug in NTRAND3.3, pow-

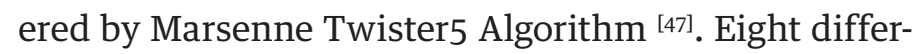
ent numerical tests were arranged; one for each stage of all conditions, in a way that all the participants were subjected to the same level of difficulty under the same lighting conditions (Figure 8).

Performance was considered in our experiment as the more exact the count was done in each numerical test in a 250/250 correct answers and then recorded in terms of percentage/ratio of accomplishment for later statistical analysis.

As in each lighting condition (A,B,C and D), the participants had to make 2 numerical tests on each of them; the numerical tests were called "stage 1 " and "stage 2", as variables such as performance, or pupil size could be affected for the time of exposure.

The purpose of the test was to sustain a steady brain activity under the lighting conditions by counting the number of appearances of each number in a given page.

\begin{tabular}{|c|c|c|c|c|c|c|c|c|c|c|}
\hline 8 & 6 & 1 & 5 & 0 & 1 & 9 & 5 & 3 & 5 & CONDITION \\
\hline 7 & 5 & 4 & 7 & 0 & 10 & 6 & 2 & 2 & 2 & 3 \\
\hline 2 & 3 & 7 & 1 & 2 & 1 & 6 & 0 & 8 & 7 & \\
\hline 4 & 7 & 9 & 2 & 9 & 10 & 2 & 7 & 7 & 5 & TEST 2 \\
\hline 6 & 1 & 2 & 6 & 9 & 2 & 9 & 4 & 5 & 0 & \\
\hline 4 & 3 & 5 & 3 & 1 & 6 & 5 & 10 & 8 & 5 & \\
\hline 9 & 4 & 1 & 5 & 6 & 3 & 7 & 7 & 5 & 8 & 0 \\
\hline 4 & 2 & 2 & 6 & 4 & 5 & 5 & 10 & 8 & 9 & 1 \\
\hline 1 & 1 & 9 & 6 & 2 & 7 & 0 & 4 & 10 & 2 & \\
\hline 8 & 4 & 8 & 4 & 8 & 1 & 4 & 4 & 6 & 8 & 2 \\
\hline 7 & 7 & 6 & 6 & 8 & 1 & 8 & 5 & 2 & 10 & 3 \\
\hline 5 & 4 & 4 & 1 & 2 & 9 & 1 & 10 & 9 & 6 & \\
\hline 2 & 4 & 2 & 4 & 5 & 6 & 9 & 7 & 6 & 6 & 4 \\
\hline 8 & 5 & 5 & 1 & 1 & 8 & 10 & 8 & 0 & 3 & 5 \\
\hline 2 & 1 & 6 & 7 & 2 & 6 & 7 & 7 & 0 & 9 & \\
\hline 8 & 7 & 2 & 0 & 4 & 4 & 9 & 2 & 2 & 9 & 6 \\
\hline 7 & 6 & 5 & 0 & 10 & 4 & 6 & 2 & 7 & 1 & 7 \\
\hline 1 & 7 & 4 & 4 & 1 & 2 & 0 & 8 & 6 & 7 & \\
\hline 2 & 3 & 1 & 3 & 9 & 9 & 9 & 9 & 1 & 8 & 8 \\
\hline 5 & 4 & 1 & 6 & 2 & 4 & 6 & 3 & 4 & 8 & 9 \\
\hline 0 & 1 & 10 & 0 & 8 & 8 & 9 & 9 & 8 & 8 & \\
\hline 3 & 8 & 4 & 2 & 7 & 1 & 8 & 9 & 5 & 8 & 10 \\
\hline 7 & 7 & 6 & 3 & 9 & 7 & 6 & 1 & 7 & 10 & \\
\hline 3 & 5 & 0 & 9 & 8 & 6 & 2 & 4 & 1 & 5 & \\
\hline 1 & 10 & 8 & 0 & 0 & 3 & 2 & 7 & 7 & 8 & \\
\hline
\end{tabular}

FIGURE 8. Numerical Test sample.

Before each daily intervention, all the equipment was carefully calibrated according to the manufacturer's specifications, the type of equipment used in all measurements has own steps to calibrate before each take. The experimenter as all laboratory members in the research section has to undertake a six month training course on the equipment before using it.

The EEG was recorded using the MP150 System, BIOPAC Systems Inc. ${ }^{\circledR}$ by positioning the electrodes (BIOPAC Systems Inc. ${ }^{\circledR}$, EL254S; Silver-silver chloride,$\mathrm{Ag}-\mathrm{AgCl})$ at the occipital $(\mathrm{Oz})$ and the central (Cz) scalp locations according to the International 10-20 system in a non-invasive procedure; the placement of the electrodes is done by measuring the scalp and identifying 
the locations, then fixing them manually by adding conductive paste (Elefix, Z-181JE). A third electrode has to be placed on the earlobe as a point of reference ('ground') of the body's baseline voltage due to other electrical activities (noise). Electrodes for Electrooculogram (EOG measurements are generated due to the eye's movement during the test) were also placed; this EOG's electrodes are located one above and one below each eye over the Orbicularis oculi muscle. Impedance on all electrodes was kept at $<5 \mathrm{~K} \Omega$, and revised with impedance measurement device MaP811 (Nihon sound tech MAP No. 116-032).

Occipital and Central locations were selected as presence of light and the primary visual cortex is most related to the Occipital lobe rather than the frontal lobe where Cognitive work in brain is normally measured ${ }^{[44]}$. Data was acquired at $1 \mathrm{Khz}, 1$ second epochs were taken but full raw data was considered as the base measure, once is recorded; EOG's artefacts were removed by filtering the channels (BIOPAC Systems Inc. ${ }^{\circledR}$, Acknowledge software V4.1). Then, data was processed by Fast Fourier Transform function (FFT) and data is band pass filtered for posterior analysis in frequencies of brain responses, 4-8 $\mathrm{Hz}$ for Theta waves, 8-13 Hz for Alpha, 13-30 Hz for Beta and 31-45 $\mathrm{Hz}$ for Gamma waves; were the ranges used.

The BP-LED flickering rate was generated using a pulse width modulation signal delivered by a programmable board (mbed ${ }^{\circledR}$, NXP LPC1768, LPCXpresso BOARD, ARM Corp. LTD.), and then verified using an oscilloscope (TEKTRONIX ${ }^{\circledR}$, TPS 2024B). The pulse rate was maintained at $100 \mathrm{~Hz}$ ( $1 \mathrm{~ms}$ for 'on' state and $9 \mathrm{~ms}$ for 'off' state). The LED used in the flickering lamp was a high power blue LED (16 $W$ 24-AB2S, KASHINOKI SOGYO CO., LTD.), with a peak frequency level at $466 \mathrm{~nm}$.

The irradiance was set at $15 \mu \mathrm{W} / \mathrm{cm}^{2}$ for the blue LED and checked using the CL500A, Konica ${ }^{\circledR}$ Minolta Optics Inc. meter (Figure 5 for SPD).
Pupil size was measured in order to verify if by the insertion of BP-LED there is a significant change in contraction or dilation; besides the one denoted for the intervention of different light color temperatures; as it has been previously studied that Pupil size is related to cognitive effort ${ }^{[56]}$.

Pupil size was recorded by using a hand held recording device with integrated camera, View SHOT FP-10000TM, TMI Corp., Japan; this equipment takes video of the pupil size while the subject is looking to a target in the illuminated surface of the desk, through the view chamber of the device and generates a continuous data file of the recorded size of the pupil.

Heart rate was measured by using Portapres Model2TM, ZeroCSeven, using one finger cuff for the 5 minutes measurement test (per 2 stages) in each condition. An air compressor integrated to a belt regulates the pressure sent to the finger cuff while data of HR is recorded in the Portapres Model-2TM, ZeroCSeven Portapres Control Unit (S/N 01.08.M2. CU.404) device; by connecting the finger cuff cable and the air hose to it. The Control Unit device has a calibration process to follow for each subject measured; every morning before the start the equipment was calibrated to the specific person by entering his/her data (height, weight, sex and age) and by resetting to zero the height correction unit of the Portapres Model-2TM.

Both measures, pupil size so as heart rate, were taken to include in the analysis consideration of possible inclusion or exclusion of data among the repeated measures, they were not only intended to be a control measures for the participant's homeostasis behaviour.

All the equipment used at the laboratory is not for clinical or illnesses diagnostics, these devices are designed to record data for non-invasive experimental procedures only. 
At the end of each lighting condition, the participants were given a questionnaire to record their qualitative evaluation about the condition.

The questions were related to the comfort level, light perception, colour temperature, drowsiness, eye strain, headache, readability, flicker perception, workability, quality of light, and colour change perception (Figure 9).

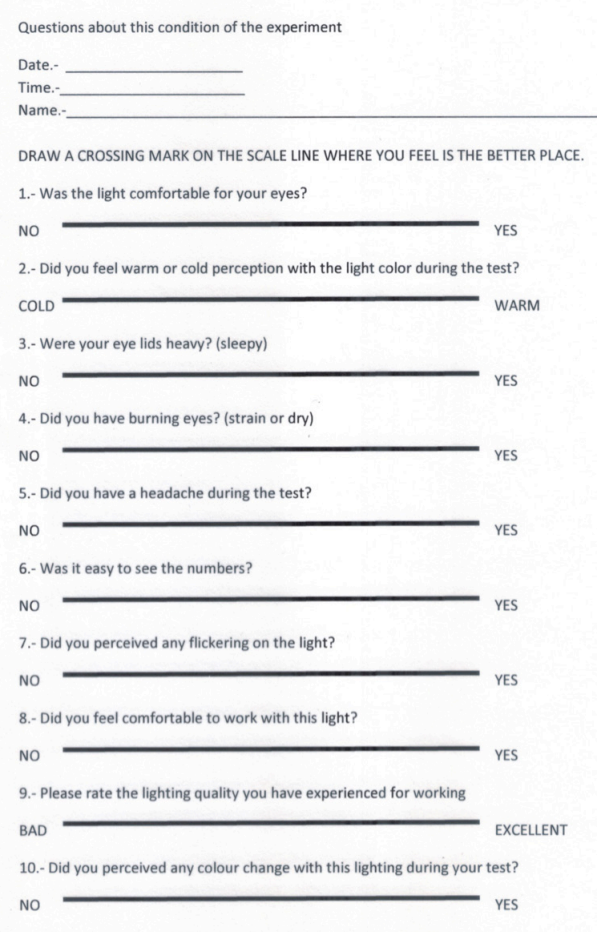

FIGURE 9. Qualitative Questionnaire.

It was based in a previous study on the lighting quality scale, developed by Boyce, et al., (2003) [2]; questions were modified to fit the purpose of our study and a preexperiment was done to sensitize the usefulness of it. By using the Visual Analogue Scale format for its accuracy in data, but knowing that, although significance may arose; interpretation has to be carefully analysed.

\section{Procedures}

This study was designed as a true experiment. All participants received every treatment in a counterbalanced procedure (Multiple crossover), there was no control group; thus, it is considered a longitudinal analysis with repeated measures, single blinded type of experiment ${ }^{[48]}[49]$.

Treatments were sorted in a counterbalanced procedure by using the Balanced Latin Square Design [50] [51] To avoid carry over effect, fatigue or learning curve on the data due to the "stages" involved on each treatment. Counterbalanced sequence was randomly assigned to each participant, so they did not known the sequence of treatments they were receiving.

The participants were personally instructed to have a good sleep the previous night without consuming alcohol, caffeinated beverages, or sweets; not having worked in shifts or travelled across time zones in the previous month.

They had to participate in two different days (each day = two treatments and 2 stages on each treatment). They freely chose (according to their availability) consecutive days or separate days, some even with 2 weeks in between days of collaboration, considering this as a randomized allocation as there was no restraint in the date selection.

The participants arrived at 10:00 a.m. on the selected day. During the first $30 \pm 5 \mathrm{~min}$, the electrodes of the EEG and the heart rate (HR) measuring device were placed and adjusted. Simultaneously, the participants faced the desk surface, which had already been set for the first lighting condition to be measured; this was the adaptation period.

The experiment was conducted between 10:00 am to $12: 00$ p.m. in order to coincide with what is recognized as the lowest melatonin secretion time during the day ${ }^{[52]}$. Only one participant per day and was exposed to two lighting conditions in that day, with two numerical tests (called "stages") for each lighting condition. 
TABLE 4. Experimental procedure.

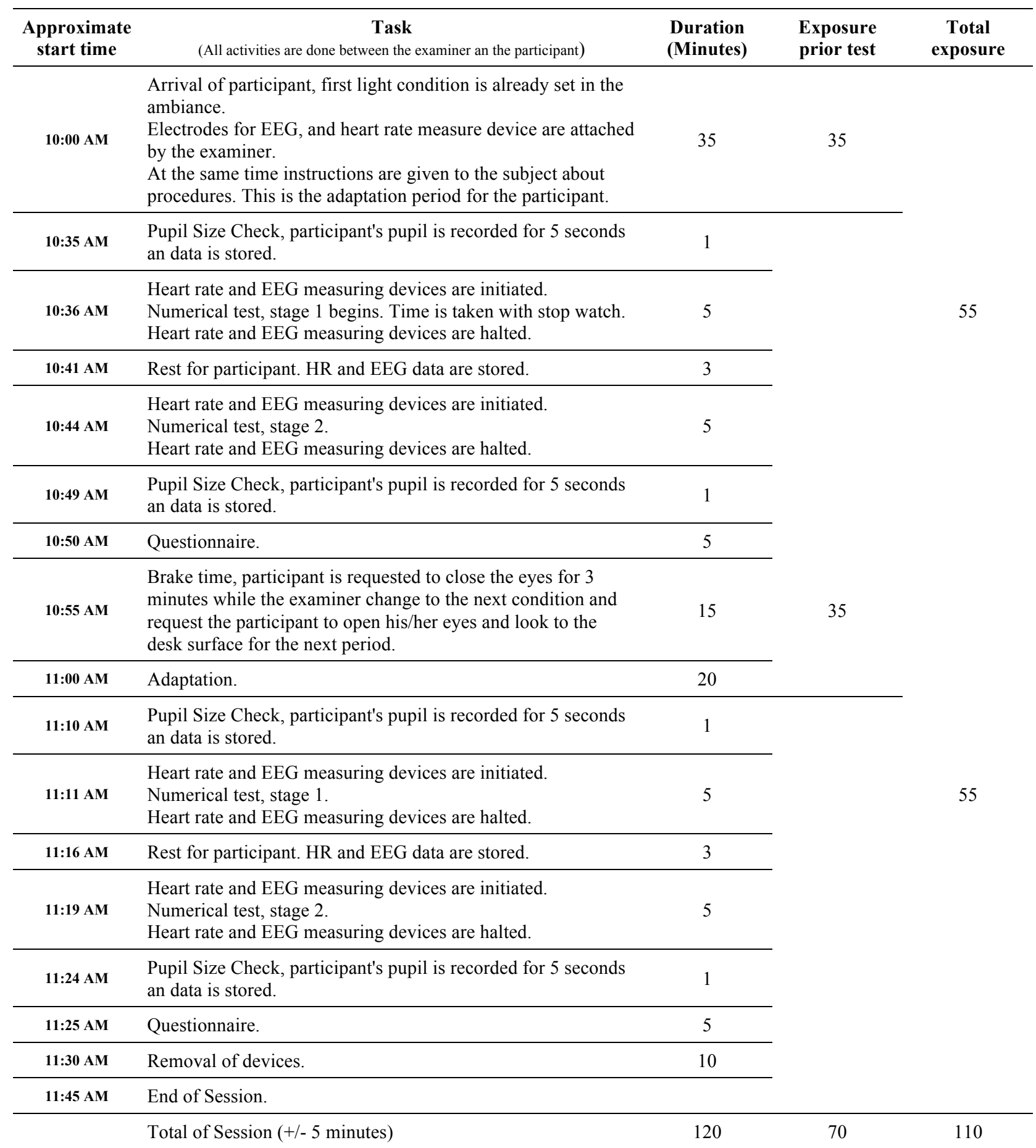

The subjects performed the experiment as shown in Table 4 and Figure 10. During the process, measures of pupil size were taken for 5 seconds prior to the first numerical test, and for another 5 seconds at the end of the second numerical test of each condition. To review changes before and after the exposure to the light condition; eyes were requested to be fully open during 5 seconds while they were looking through the handheld 


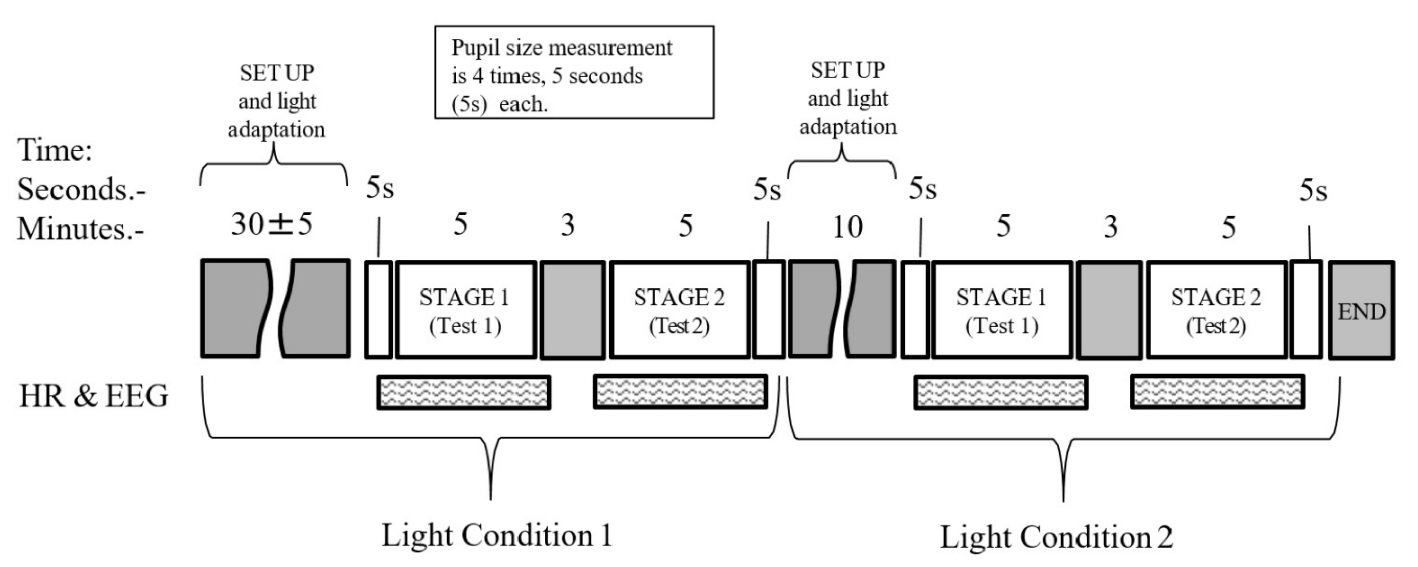

FIGURE 10. Experimental procedure diagram for one day of the test.

viewer at a target previously drawn on the desk surface. They were asked to seat in a straight, reading like position and to keep both eyes open during each take.

For the statistical analysis, normality was assumed and as data on our dependent variables was measured on a continuous scale, hence a parametric test was chosen and Pearson's product-moment correlation coefficient applied. The sample $\mathrm{N}=14$, data was expected to have statistical significance of $\mathrm{p}<0.05$, and a $\mathrm{p}<0.1$ for a tendency consideration of change if larger sample is applied in later tests.

The data were collected from various sources and processed in the IBM SPSS ${ }^{\circledR}$, v20 software by analysing the Pearson product-moment correlation coefficient and by repeatedly conducting the analysis of variance (ANOVA) in a $2 \times 2 \times 2$ matrix that compared the light colour temperature (LCT), BP-LED intervention, and the above-mentioned factors at the two stages of each lighting conditions; after which Bonferroni's post hoc test was evaluated for significance. These were applied to the entire physiological data.

Independent variables in the ANOVA analysis were the LCT, BP/LED and the numerical test; dependent or non-controlled variables were those such as the intrinsically noise in a measurement like those related in how the participants executed the numerical test, also the data collected from physiological measurements, pupil size, heart rate, performance and EEG behaviour.

The questionnaire was processed by the same software, data was subject to student's paired t-test, and analysed for every lighting condition in each question.

\section{RESULTS}

A Pearson product-moment correlation coefficient was computed in order to find the Pearson's strength of relationship " $r$ " among the sample " $n$ " and their statistical significance " $\mathrm{p}$ " $(\mathrm{p}<.05)$. The EEG readings generated maximum correlational data. The participants' alertness were positively correlated with the $\mathrm{Cz}$ gamma waves at $\mathrm{r}=0.611, \mathrm{n}=14, \mathrm{p}=0.020$, and the $\mathrm{Cz}$ beta/gamma proportion at $\mathrm{r}=0.584, \mathrm{n}=14, \mathrm{p}=0.028$. Both the correlations were operated under condition 'B' (low colour temperature and BP-LED intervention), which implied a higher alertness, and therefore, presence of a large number of beta and gamma waves.

Negative correlations were found in the $\mathrm{Cz}$ alpha waves operating under condition 'B' at $\mathrm{r}=-0.551, \mathrm{n}=$ $14, \mathrm{p}=0.41$, and under condition ' $\mathrm{D}$ ' at $\mathrm{r}=-0.650, \mathrm{n}=$ $14, \mathrm{p}=0.12$. In addition, there was a statistically significant correlation of condition ' $\mathrm{B}$ ' in the $\mathrm{Cz}$ alpha/ beta proportion at $\mathrm{r}=-0.573, \mathrm{n}=14, \mathrm{p}=0.32$. 
To confirm this behaviour, a plot of $\mathrm{Cz}$ beta versus $\mathrm{Cz}$ alpha and $\mathrm{Oz}$ beta versus $\mathrm{Oz}$ alpha were reviewed. The data obtained for the first pair of variables were $r=-671$, $\mathrm{n}=14, \mathrm{p}=0.009$, and that for the $\mathrm{Oz}$ correlation was $\mathrm{r}=$ -730, $\mathrm{n}=14, \mathrm{p}=0.003$. Both the cases were operated under condition ' $\mathrm{B}$ ', similar to the $\mathrm{Cz}$ alpha/beta proportion mentioned above. This shows a behaviour indicating the influence of the BP-LED when it is active in conjunction with a low colour temperature light.

\section{Repeated measures ANOVA}

\section{Performance}

There was a statistical tendency $(\dagger)$ in the interactions of the BP-LED during the different lighting conditions, as shown in Figure 11, with Wilks' $\Lambda=0.781, \mathrm{~F}(1,13)=$ 3.636, $\mathrm{p}=0.079$, and partial $\eta^{2}=0.219$.

This tendency indicates a possible decrease in the performance in those lighting conditions where the BP-LED intervenes, which is consistent with the abovementioned correlation results of the $\mathrm{Cz}$ alpha wave (Figure 11).

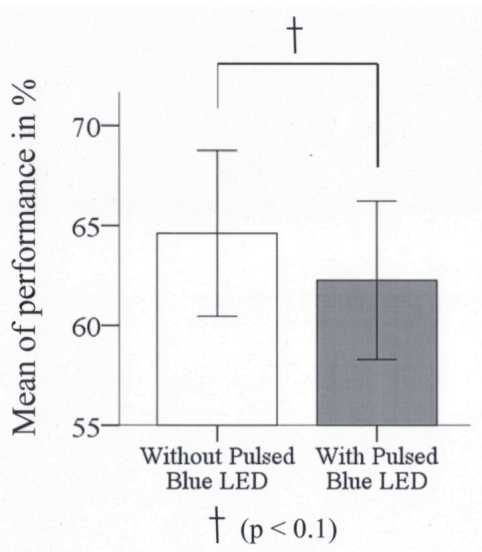

FIGURE 11. Performance and intervention of BP-LED effect.

The other factors (heart rate and pupil size) did not exhibit any statistical significance on the performance factor when a condition of the BP-LED was executed (see Table 5 Standard Deviation values in relation to Means for the respective light condition).

\section{Heart rate}

The results showed a significant decrease in the HR at the light colour temperature factor with Wilks' $\Lambda=$ $0.633, \mathrm{~F}(1,13)=7.537, \mathrm{p}=0.017$, and partial $\eta^{2}=0.367$, as shown in Figure 12.

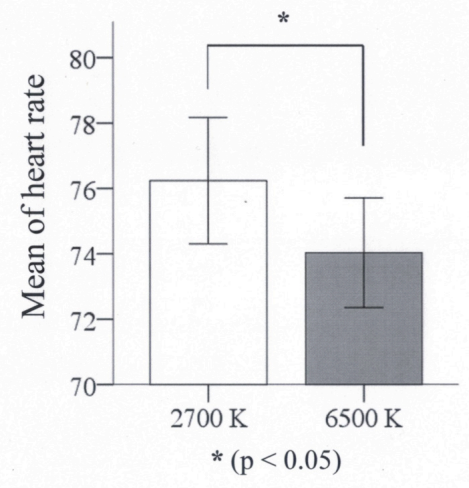

FIGURE 12. Heart rate and light colour temperature effect.

\section{Electroencephalogram variable}

It was found that alpha waves measured in the $\mathrm{Cz}$ location responded with a statistical significance in the two stages with Wilks' $\Lambda=0.696, \mathrm{~F}(1,13)=5.668$, $\mathrm{p}=0.033$, and partial $\eta^{2}=0.304$, as shown in Figure 13 .

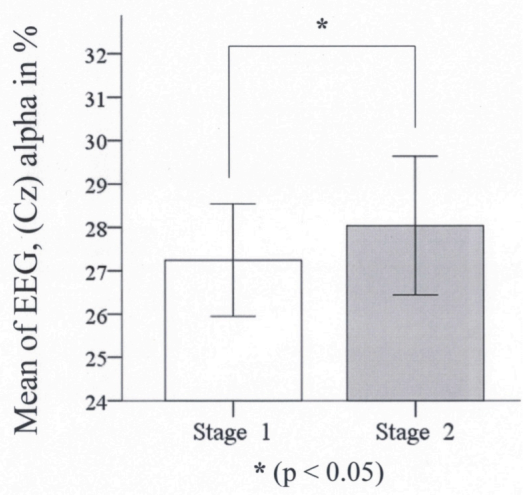

FIGURE 13. EEG (Cz) alpha waves in the two stages.

Furthermore, it was found that the alpha waves measured in the Oz location responded with a statistical significance in the two stages of the tests with Wilks' $\Lambda=0.726, \mathrm{~F}(1,13)=4.905, \mathrm{p}=0.045$, and partial $\eta^{2}=0.274$, as shown in Figure 14. These two alpha locations indicated a possible decrease in alertness during the test. 


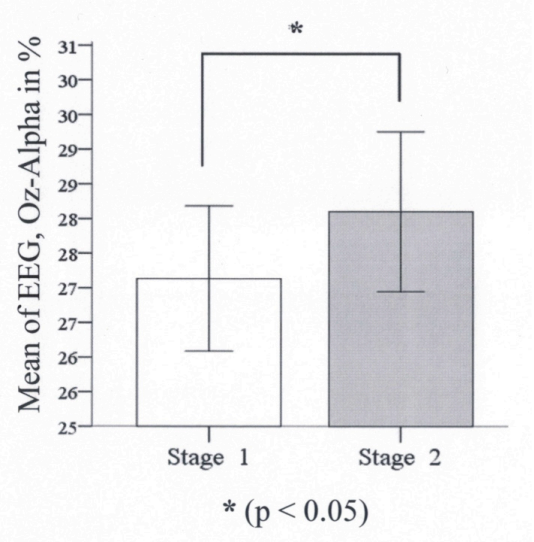

FIGURE 14. EEG (Oz) alpha waves in the two stages.

The gamma waves measured in the $\mathrm{Oz}$ location responded with a statistical significance in the interaction of the two stages of light colour temperature and intervention of BP-LED; test with Wilks' $\Lambda=0.729, \mathrm{~F}$ (1, 13) $=4.825, p=0.047$, and partial $\eta^{2}=0.271$, as shown in Figure 15. This was opposite to the behaviour of the gamma waves in the conditions with the BP-LED intervention. It indicates the presence of fewer gamma waves compared to those without the BP-LED intervention. This can be misunderstood as a decreasing effect on alertness under these conditions. Therefore, an analysis of the behaviour of the gamma waves as a complement to the beta waves or an actual decrease in its number was also carried out.

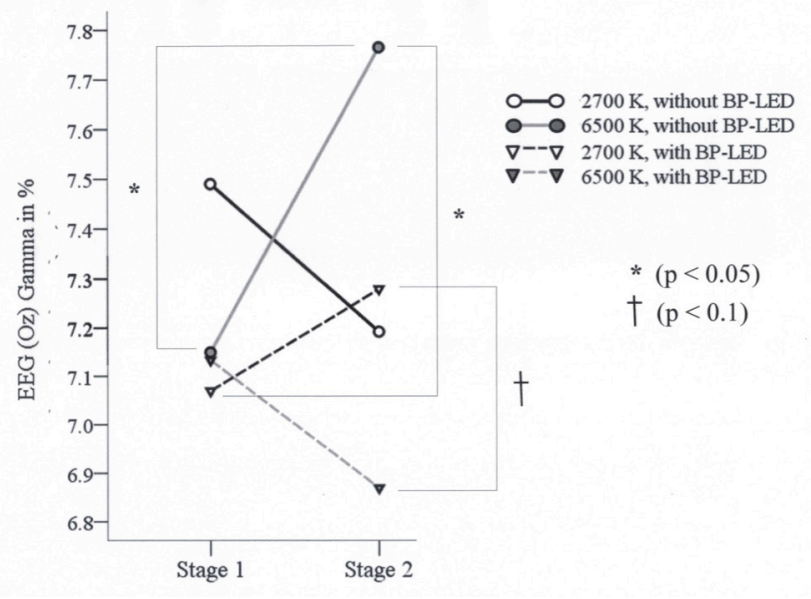

FIGURE 15. EEG (Oz) gamma waves in interaction among; the two stages, the light colour temperature and the BP-LED intervention factors.
The following outcomes were obtained from the ratio of the beta wave with respect to the gamma wave in the $\mathrm{Oz}$ location where they displayed a Wilks' $\Lambda=$ 0.669, $\mathrm{F}(1,13)=6.444, \mathrm{p}=0.025$, and partial $\eta^{2}=$ 0.331, as shown in Figure 16.

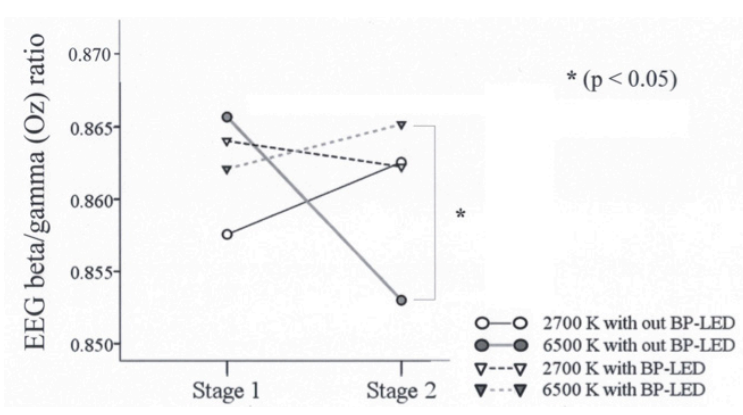

FIGURE 16. EEG (Oz) beta/gamma wave's ratio in interaction among; the two stages, the light colour temperature and the BP-LED intervention factors.

In the $\mathrm{Oz}$ location, the ratio of the beta waves with respect to the alpha waves was higher in the first stage than in the second stage with Wilks' $\Lambda=0.747, \mathrm{~F}(1,13)$ $=4.403, \mathrm{p}=0.056$, and partial $\eta^{2}=0.253$, as shown in Figure 17 (see Table 5 Standard Deviation values in relation to Means for the respective light condition).

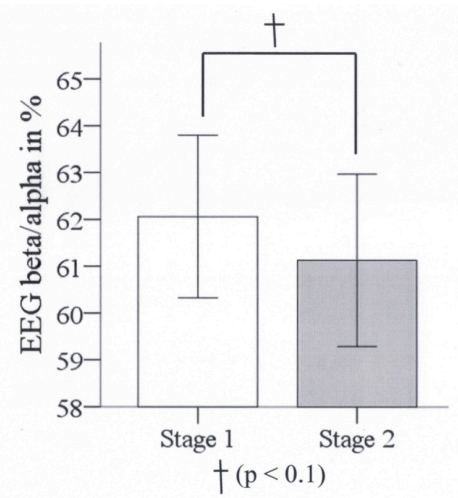

FIGURE 17. EEG (Oz) beta/alpha waves proportion in the two stages.

\section{Qualitative questionnaire}

The analysis revealed a data tendency in questions related to comfort levels by the interaction of BP-LED and light colour temperature at Wilks' $\Lambda=0.764, \mathrm{~F}$ (1, 13) $=4.013, p=0.066$, and partial $\eta^{2}=0.236$. There was 
TABLE 5. Standard deviation values in relation to means for the respective light condition.

\begin{tabular}{|c|c|c|c|c|c|c|c|c|c|}
\hline CONDITION & & $\mathrm{A}$ & $\mathrm{A}$ & $\mathrm{B}$ & $\mathrm{B}$ & $\mathrm{C}$ & $\mathrm{C}$ & $\mathrm{D}$ & $\mathrm{D}$ \\
\hline STAGE & & ST1 & ST2 & ST1 & ST2 & ST1 & ST2 & ST1 & $\mathrm{ST} 2$ \\
\hline Light color temperature & & $2700 \mathrm{~K}$ & $2700 \mathrm{~K}$ & $2700 \mathrm{~K}$ & $2700 \mathrm{~K}$ & $6500 \mathrm{~K}$ & $6500 \mathrm{~K}$ & $6500 \mathrm{~K}$ & $6500 \mathrm{~K}$ \\
\hline Blue Pulsed LED & & No & No & Yes & Yes & No & No & Yes & Yes \\
\hline \multirow{2}{*}{ PERFORMANCE } & MEAN & $64.8 \%$ & $65.2 \%$ & $60.1 \%$ & $63.1 \%$ & $63.3 \%$ & $65.2 \%$ & $65.0 \%$ & $60.9 \%$ \\
\hline & SD & $16.1 \%$ & $17.2 \%$ & $15.7 \%$ & $12.5 \%$ & $14.4 \%$ & $15.9 \%$ & $15.8 \%$ & $16.1 \%$ \\
\hline \multirow{2}{*}{ Pupil Size } & MEAN & 10.07 & 9.93 & 10.90 & 10.79 & 9.23 & 9.42 & 9.27 & 9.71 \\
\hline & SD & 5.13 & 4.88 & 5.14 & 5.44 & 4.58 & 5.41 & 4.62 & 4.13 \\
\hline \multirow{2}{*}{ Heart Rate } & MEAN & 76.31 & 76.43 & 76.18 & 76.04 & 74.52 & 75.22 & 73.13 & 73.29 \\
\hline & SD & 8.44 & 7.74 & 6.32 & 7.02 & 6.76 & 6.43 & 5.30 & 6.85 \\
\hline \multirow{2}{*}{ EEG CzT } & MEAN & 36.59 & 35.99 & 37.53 & 35.14 & 37.31 & 37.75 & 40.76 & 38.27 \\
\hline & SD & 6.11 & 5.63 & 4.83 & 6.89 & 6.94 & 8.32 & 10.09 & 6.28 \\
\hline \multirow{2}{*}{ EEG CzA } & MEAN & 27.06 & 27.55 & 27.55 & 29.56 & 27.17 & 26.50 & 27.19 & 28.53 \\
\hline & $\mathrm{SD}$ & 5.31 & 4.49 & 5.59 & 8.21 & 3.85 & 5.32 & 5.00 & 5.44 \\
\hline \multirow{2}{*}{ EEG CzB } & MEAN & 32.76 & 32.98 & 31.54 & 31.72 & 31.91 & 31.43 & 29.01 & 29.97 \\
\hline & $\mathrm{SD}$ & 7.05 & 6.55 & 6.28 & 7.68 & 6.36 & 7.65 & 7.85 & 5.19 \\
\hline \multirow{2}{*}{ EEG CzG } & MEAN & 3.58 & 3.48 & 3.38 & 3.59 & 3.61 & 4.32 & 3.04 & 3.22 \\
\hline & SD & 1.53 & 0.93 & 1.03 & 1.41 & 1.40 & 3.43 & 1.12 & 1.27 \\
\hline \multirow{2}{*}{ EEG OzT } & MEAN & 19.99 & 19.79 & 21.33 & 19.79 & 20.25 & 19.82 & 21.26 & 20.25 \\
\hline & SD & 6.08 & 6.36 & 7.32 & 6.87 & 7.81 & 6.69 & 6.11 & 6.11 \\
\hline \multirow{2}{*}{ EEG OzA } & MEAN & 27.92 & 28.04 & 26.62 & 27.70 & 26.75 & 27.46 & 27.26 & 29.20 \\
\hline & SD & 3.41 & 3.59 & 4.55 & 4.96 & 3.59 & 5.01 & 4.29 & 3.73 \\
\hline \multirow{2}{*}{ EEG OzB } & MEAN & 44.60 & 44.98 & 44.99 & 45.22 & 45.86 & 44.95 & 44.35 & 43.68 \\
\hline & SD & 6.12 & 7.00 & 9.09 & 8.29 & 7.67 & 8.59 & 6.96 & 6.02 \\
\hline \multirow{2}{*}{ EEG OzG } & MEAN & 7.49 & 7.19 & 7.07 & 7.28 & 7.15 & 7.77 & 7.13 & 6.87 \\
\hline & $\mathrm{SD}$ & 2.39 & 1.72 & 1.92 & 1.84 & 1.91 & 2.11 & 1.86 & 1.76 \\
\hline
\end{tabular}

a statistical tendency in workability at Wilks' $\Lambda=0.741$, $\mathrm{F}(1,13)=4.555, \mathrm{p}=0.052$, and partial $\eta^{2}=0.259$ during the same interaction of the BP-LED and the light colour temperature (Table 6).

\section{DISCUSSION}

The outcomes of the experiment were compelling. The data provided information about the physiological behaviour of humans in a particular light environ- ment. The process followed a normal workday sequence, and therefore, the effects obtained provided clues to simulate an adequate lighting condition that, as per the data, is consistent with what has been called a dynamic light scenario [53].

The results obtained were accordingly related to the aim of this paper; and data for answering to the research question was also obtained. 
TABLE 5. Standard deviation values in relation to means for the respective light condition.

\begin{tabular}{|c|c|c|c|c|c|c|c|c|c|c|c|c|}
\hline \multicolumn{13}{|c|}{ Subjetive Questionnaire Responses } \\
\hline \multirow[b]{2}{*}{ Question } & \multirow[b]{2}{*}{ Type of response } & \multicolumn{2}{|c|}{ Condition "A" } & \multicolumn{2}{|c|}{ Condition "B" } & \multicolumn{2}{|c|}{ Condition "C" } & \multicolumn{2}{|c|}{ Condition "D" } & \multirow{2}{*}{$\begin{array}{c}\begin{array}{c}\text { Color } \\
\text { temperature }\end{array} \\
\text { P Value }\end{array}$} & \multirow{2}{*}{$\begin{array}{c}\text { Blue } \\
\text { pulsed LED } \\
\text { P Value }\end{array}$} & \multirow{2}{*}{$\begin{array}{c}\text { Interaction } \\
\text { of color } \\
\text { temperature } \\
\text { and BP-LED } \\
\text { P Value }\end{array}$} \\
\hline & & Mean & $\pm \mathbf{S D}$ & Mean & \pm SD & Mean & \pm SD & Mean & \pm SD & & & \\
\hline Comfortability & High is better & 6.521 & 1.225 & 7.000 & 1.479 & 6.864 & 1.515 & 6.029 & 2.027 & 0.469 & 0.592 & 0.066 \\
\hline $\begin{array}{l}\text { LC Temperature } \\
\text { perception }\end{array}$ & Warm or Cold & 7.579 & 1.089 & 7.029 & 1.756 & 3.871 & 2.226 & 3.529 & 1.522 & 0.000 & 0.400 & 0.605 \\
\hline Drowsiness & Low is better & 3.807 & 2.811 & 3.321 & 2.158 & 2.886 & 2.388 & 4.064 & 2.690 & 0.860 & 0.435 & 0.189 \\
\hline Eye strain & Low is better & 3.464 & 2.916 & 2.464 & 1.998 & 2.971 & 2.476 & 3.929 & 3.103 & 0.331 & 0.964 & 0.235 \\
\hline Headache & Low is better & 0.971 & 1.064 & 0.857 & 0.907 & 0.771 & 0.867 & 1.271 & 1.898 & 0.647 & 0.584 & 0.194 \\
\hline Readability & High is better & 6.143 & 2.073 & 6.164 & 2.162 & 6.514 & 1.939 & 6.614 & 2.166 & 0.446 & 0.883 & 0.905 \\
\hline Flickering & Low is better & 0.950 & 0.943 & 1.014 & 0.920 & 0.929 & 0.856 & 1.050 & 0.888 & 0.954 & 0.367 & 0.903 \\
\hline Workability & High is better & 6.100 & 1.666 & 6.914 & 1.615 & 6.150 & 2.004 & 5.957 & 1.977 & 0.409 & 0.612 & 0.052 \\
\hline Quality & High is better & 5.557 & 1.399 & 6.193 & 1.352 & 6.279 & 1.747 & 5.900 & 1.846 & 0.731 & 0.737 & 0.017 \\
\hline $\begin{array}{l}\text { Color change } \\
\text { perception }\end{array}$ & Low is better & 1.279 & 1.953 & 0.986 & 0.807 & 0.750 & 0.833 & 0.757 & 0.788 & 0.194 & 0.406 & 0.616 \\
\hline
\end{tabular}

Heart Rate revealed that data indicate an incremental influence of the low colour temperature on the behaviour of the participant. This influence might be caused by the possible influence of the red component from the low colour temperature light spectrum (see Table 4 Standard Deviation values in relation to Means for the respective light condition).

It was assumed that the red component of the low colour temperature light spectrum perchance evoked a slight increase in alertness levels as it was continuously being emitted throughout the ambiance; if so, this is consistent with the statement that red light also improves alertness ${ }^{[54]}$.

Heart rate and pupil size did not exhibit any statistical significance on the performance factor when a condition of the BP-LED was executed (see Table 4 Standard Deviation values in relation to Means for the respective light condition), it was interesting to find that pupil size is larger during BP-LED presence than without it, although not statistically significant; it is possibly due to the consistence to the statement that pupil size increases when cognitive work is being developed ${ }^{[56]}$.

Regarding the intervention of the BP-LED among light colour temperatures; the low colour temperature condition revealed that it might be the factor that influenced the increase in alertness, as resulted by the EEG beta/gamma wave analysis.

However, the EEG beta/alpha waves had a positive correlation in the scenario with low colour temperature and BP-LED interventions, as can be seen in the results plotted between $\mathrm{Cz}$ beta and $\mathrm{Cz}$ Alpha so as $\mathrm{Oz}$ beta versus $\mathrm{Oz}$ alpha into the Pearson product-moment correlation coefficient analysis (3rd paragraph). This could imply that the lighting condition had a positive effect on the workload sensation in the participants.

About the alertness being affected by workload; the EEG outcomes provided more interesting data analysis. 
The alpha waves exhibited an increasing tendency in the two stages of each lighting condition with a probable decrease in alertness levels. On the other hand, the beta waves showed a decreasing tendency under the same factors in which the alpha waves increased, under the same lighting conditions. This can be associated to the workload that the numerical test evoked as it had to be performed in a specific time frame.

In the interaction of the light colour temperature and the BP-LED intervention in the different stages of the lighting conditions, the behaviour of the beta/gamma waves revealed an increase in the value of the high colour temperature compared to its significant decrease without the BP-LED intervention as seen on Figure $16(\mathrm{p}<0.05)$ where the compelling data is the one among the $6500 \mathrm{~K}$ light colour temperature condition and the inclusion or not of the BP-LED. Furthermore, there was a decreasing behaviour in the beta/gamma waves at low colour temperature ('C' condition); however, it was not significant. Probably indicated that a large number of gamma waves were present at the low colour temperature with the BP-LED intervention.

These results revealed an important relation between the influence of BP-LED intervention and alertness levels. During exposure, the number of beta waves was almost equal in both the lighting conditions. On the other hand, in the lighting conditions without the BP-LED, it was clear and statistically significant that in the high colour temperature condition, the number of beta waves decreased. These data shows a positive effect of the BP-LED in the presence of either low or high colour temperature light conditions that help to maintain stable alertness levels unlike in the absence of BP-LED intervention where alertness levels tend to decrease significantly. The data of the beta/gamma ratios provided a complementary understanding of the behaviour of the gamma waves as described previously in Figure 13.
In the qualitative analysis, although some questions revealed no statistical significance, in some cases that could be considered an acceptable result. Flickering perception, for example, had a $\mathrm{p}=0.903$ and low mean values thus indicating there is no perception of it, which is a good indicator of a not harmful effect of BP-LED; consistent with drowsiness, eye strain and head ache related questions, that also revealed no statistical significant $\mathrm{p}$ values.

This data revealed the subjective preference of the participants to the low colour temperature condition over high colour temperature condition and no harmful effects on participants (Table 5).

\section{CONCLUSION}

It is clear from this experiment that large physiological changes under light exposures may take a significant amount of time to become appreciably perceivable even at short exposure times. Nevertheless, this can help to figure out how to enable people to start their day in a good mood and with high levels of alertness ${ }^{[55]}$.

The performance of the participants did not exhibit an increase under the lighting conditions where the BP-LED was used compared to those in which it was not. This could be due to the lack of effectiveness in the mode of answering the test; however, this does not imply that alertness was not evoked as it was analysed by the EEG data.

It is important to notice that, based on the opinions of the participants, the low colour temperature and the BP-LED provided better comfort levels and it actually improved alertness as demonstrated with the increase in the EEG beta waves. Moreover, the BP-LED intervention in a high colour temperature ambiance enabled the participants to maintain alertness levels compared to those lighting conditions where the BP-LED was absent, it is important to mention not to forget that these tests were done during the morning time, fur- 
ther tests have to be carried out for the rest of the day to determine the possible usage of a BP-LED addition to a task lamp.

Social and Organization implications could arise if an implementation of BP-LED light for a workplace's illumination is done; as this could have benefits in the increase of alertness in personnel thus eliminating drowsiness during working hours and improving performance. Anyhow it is still recommended to further investigate possible affections to the circadian rhythm if the use of this type of added light is applied for long periods of time, or if it is used for people who is working overtime or in shifts.

The results present an effect of the BP-LED on alertness levels, and therefore provide further research opportunities in indoor lighting design conditions to induce positive responses during the office hours or work under different lighting conditions such as those in hospitals, "blue rooms" of medical centre's, classrooms, among others.

Although it is not a conclusive statement this study can give an idea on how to make further studies to analyse how BP-LED could affect to health, alertness and circadian rhythm in the long term.

As a final result for our main objective, once our Hypothesis was proved from the experiment; we can then conclude that the development of a controller is a viable idea to put it in addition to a task lamp as a benefit for the state of alertness in people, thus, providing a solution for a gap in the currently available technology for illumination and alertness improvement in interior spaces.

We can then recommend that inclusion of BP-LED technology in task lamps is for a benefit in the state of alertness for individuals. 


\section{REFERENCES}

[1] Vandewalle, G., Maquet, P., \& Dijk, D.-J. (2009). Light as a modulator of cognitive brain function. Trends in Cognitive Sciences, 13(10), 429-438. http://doi.org/10.1016/j.tics.2009.07.004

[2] Boyce, P. R., Veitch, J. a, Myer, M., \& Hunter, C. (2003). Lighting Quality and Office Work : A Field Simulation Study Lighting Quality and Office Work : A Field Simulation Study, (June 2015).

[3] Borisuit, A., Linhart, F., Scartezzini, J.-L., \& Munch, M. (2015). Effects of realistic office daylighting and electric lighting conditions on visual comfort, alertness and mood. Lighting Research and Technology, 47(2), 192-209. http://doi.org/10.1177/1477153514531518

[4] Baek, H., \& Min, B.-K. (2015). Blue light aids in coping with the post-lunch dip: an EEG study. Ergonomics, 139(February), 1-8. http://doi.org/10.1080/00140139.2014.983300

[5] Smolders, K. C. H. J., de Kort, Y. A. W., \& Cluitmans, P. J. M. (2012). A higher illuminance induces alertness even during office hours: Findings on subjective measures, task performance and heart rate measures. Physiology \& Behavior, 107(1), 7-16. http://doi.org/10.1016/j.physbeh.2012.04.028

[6] Wilkins, A., Veitch, J., \& Lehman, B. (2010). LED lighting flicker and potential health concerns: IEEE standard PAR1789 update. 2010 IEEE Energy Conversion Congress and Exposition, ECCE 2010 - Proceedings, (OCTOBER 2010), 171-178. http://doi.org/10.1109/ECCE.2010.5618050

[7] Miller, N. J. (2015). FLICKER : Understanding the New IEEE Recommended Practice Flicker - Terminology.

[8] Lehman, B., Wilkins, A., Berman, S., Poplawski, M., \& Johnson Miller, N. (2011). Proposing measures of flicker in the low frequencies for lighting applications. IEEE Energy Conversion Congress and Exposition: Energy Conversion Innovation for a Clean Energy Future, ECCE 2011, Proceedings, 2865-2872. http://doi.org/10.1109/ECCE.2011.6064154

[9] Aalto University School of Science and Technology Department of Electronics Lighting Unit. (2010). Chapter 4 : Lighting and energy standards and codes. Guidebook on Energy Efficient Electric Lighting for Buildings, 57-90. Retrieved from https://goo.gl/ULmglW

[10] USDOE. (2012). Building Technologies Program SSL Fact Sheet: SSL Standards and Guidelines: Apr 2012. Retrieved from http://www1. eere.energy.gov/buildings/ssl/factsheets.html

[11] Wurtman, R. (1976). The effects of light on the human body. Scientific American.

[12] Badia, P., Myers, B., Boecker, M., Culpepper, J., \& Harsh, J. R. (1991). Bright light effects on body temperature, alertness, EEG and behavior. Physiology \& Behavior, 50(3), 583-588. http://doi.org/10.1016/0031-9384(91)90549-

[13] Mott, M. S., Robinson, D. H., Walden, A., Burnette, J., \& Rutherford, A. S. (2012). Illuminating the Effects of Dynamic Lighting on Student Learning. SAGE Open, 2(2).

http://doi.org/10.1177/2158244012445585

[14] Figueiro, M. (2013). An Overview of the Effects of Light on Human Circadian Rhythms: Implications for New Light Sources and Lighting Systems Design. Journal of Light \& Visual Environment, 37(2), 51-61. http://doi.org/IEIJ130000503
[15] Smith, M. R., \& Eastman, C. I. (2009). Phase delaying the human circadian clock with blue-enriched polychromatic light. Chronobiology International, 26(4), 709-725. http://doi.org/10.1080/07420520902927742

[16] Appleman, K., Figueiro, M. G., \& Rea, M. S. (2013). Controlling light-dark exposure patterns rather than sleep schedules determines circadian phase. Sleep Medicine, 14(5), 456-461. http://doi.org/10.1016/j.sleep.2012.12.011

[17] Rea, M. S., Figueiro, M. G., Bierman, A., \& Bullough, J. D. (2010). Circadian light. Journal of Circadian Rhythms, 8(1), 2. http://doi.org/10.1186/1740-3391-8-2

[18] Jing-Shi Huang, Yoshihiro Shimomura, Tetsuo Katsuura. (2013). "Effects of Monochromatic Light on Muscle Fatigue and Its Recovery” Journal of the Human-Environment System; Vol. 16 No. 1.

[19] West, K. E., Jablonski, M. R., Warfield, B., Cecil, K. S., James, M., Ayers, M. a, Brainard, G. C. (2011). Blue light from light-emitting diodes elicits a dose-dependent suppression of melatonin in humans. Journal of Applied Physiology (Bethesda, Md. : 1985), 110(3), 619-626. http://doi.org/10.1152/japplphysiol.01413.2009

[20] Gabel, V., Maire, M., Reichert, C. F., Chellappa, S. L., Schmidt, C., Hommes, V., Cajochen, C. (2013). Effects of Artificial Dawn and Morning Blue Light on Daytime Cognitive Performance, Wellbeing, Cortisol and Melatonin Levels. Chronobiology International, 30(8), 988-997. http://doi.org/10.3109/07420528.2013.793196

[21] Katsuura, T., Ochiai, Y., Senoo, T., Lee, S., Takahashi, Y., \& Shimomura, Y. (2012). Effects of blue pulsed light on human physiological functions and subjective evaluation. Journal of Physiological Anthropology, 31(1), 23. http://doi.org/10.1186/1880-6805-31-23

[22] Figueiro, M. G., Bierman, A., \& Rea, M. S. (2013). A train of blue light pulses delivered through closed eyelids suppresses melatonin and phase shifts the human circadian system. Nature and Science of Sleep, 5, 133-41. http://doi.org/10.2147/NSS.S52203

[23] Bullough JD. (2000). “The blue-light hazard: A review”. Journal of the Illuminating Engineering Society 2000; 29: 6-14.

[24] Revell, V. L., Molina, T. a, \& Eastman, C. I. (2012). Human phase response curve to intermittent blue light using a commercially available device. The Journal of Physiology, 590(Pt 19), 4859-68. http://doi.org/10.1113/jphysiol.2012.235416

[25] Trejo, L. J., Kubitz, K., Rosipal, R., Kochavi, R. L., \& Montgomery, L. D. (2015). EEG-Based Estimation and Classification of Mental Fatigue. Psychology, 6(5), 572-589. http://doi.org/10.4236/psych.2015.65055

[26] Okamoto, Y., Rea, M. S., \& Figueiro, M. G. (2014). Temporal dynamics of EEG activity during short- and long-wavelength light exposures in the early morning. BMC Research Notes, 7(1), 113. http://doi.org/10.1186/1756-0500-7-113

[27] Vk, K., Dasari, D., \& Ding, L. (2014). EEG Correlates of Fluctuation in Cognitive Performance in an Air Traffic Control Task, (November).

[28] Sahin, L., \& Figueiro, M. G. (2013). Alerting effects of shortwavelength (blue) and long-wavelength (red) lights in the afternoon. Physiology \& Behavior, 116-117, 1-7. http://doi.org/10.1016/i.physbeh.2013.03.014 
[29] Figueiro, M. G., Bierman, A., Plitnick, B., \& Rea, M. S. (2009). Preliminary evidence that both blue and red light can induce alertness at night. BMC Neuroscience, 10(1), 105. http://doi.org/10.1186/1471-2202-10-105

[30] Münch, M., Plomp, G., Thunell, E., Kawasaki, a, Scartezzini, J. L., \& Herzog, M. H. (2014). Different colors of light lead to different adaptation and activation as determined by high-density EEG. NeuroImage, 101, 547-54. http://doi.org/10.1016/j.neuroimage.2014.06.071

[31] Harrison, E. M., Gorman, M. R., \& Mednick, S. C. (2011). The effect of narrowband 500nm light on daytime sleep in humans. Physiology and Behavior, 103(2), 197-202. http://doi.org/10.1016/j.physbeh.2011.01.02

[32] Berson, D. M. (2002). Phototransduction by Retinal Ganglion Cells That Set the Circadian Clock. Science, 295(5557), 1070-1073. http://doi.org/10.1126/science.1067262

[33] Gronfier, C. (2013). The good blue and chronobiology: Light and non-visual functions. Blue Light, Medical Scientific, 19-22.

[34] Gornicka, G. (2006). Effect of lighting level and colour temperature on alertness and vigilance during the day. Sleep-Wake Research in the Netherlands, Vol 17, 2006, 59-63.

[35] Wright, K. P., Hull, J. T., \& Czeisler, C. a. (2002). Relationship between alertness, performance, and body temperature in humans. American Journal of Physiology. Regulatory, Integrative and Comparative Physiology, 283(6), R1370-R1377. http://doi.org/10.1152/ajpregu.00205.2002

[36] Cajochen, C., Zeitzer, J. M., Czeisler, C. A., \& Dijk, D.-J. J. (2000). Dose-response relationship for light intensity and ocular and electroencephalographic correlates of human alertness. Behavioural Brain Research, 115(1), 75-83. http://doi.org/10.1016/S0166-4328(00)00236-9

[37] Williams, J., Ramaswamy, D., \& Oulhaj, A. (2006). 10 Hz flicker improves recognition memory in older people. BMC Neuroscience, 7, 21. http://doi.org/10.1186/1471-2202-7-21

[38] Figueiro, M. G., Lesniak, N. Z., \& Rea, M. S. (2011). Implications of controlled short-wavelength light exposure for sleep in older adults. BMC Research Notes, 4(1), 334. http://doi.org/10.1186/1756-0500-4-334

[39] Figueiro, M. G., Saldo, E., Rea, M. S., Kubarek, K., Cunningham, J., \& Rea, M. S. (2008). Developing Architectural Lighting Designs to Improve Sleep in Older Adults. The Open Sleep Journal, 1, 40-51. http://doi.org/10.2174/1874620900801010040

[40] Gronfier, C., Wright, K. P., Kronauer, R. E., Jewett, M. E., \& Czeisler, C. a. (2004). Efficacy of a single sequence of intermittent bright light pulses for delaying circadian phase in humans. American Journal of Physiology. Endocrinology and Metabolism, 287(1), E174-E181. http://doi.org/10.1152/ajpendo.00385.2003

[41] Wilkins, A., Veitch, J., \& P1789_Committee_Members. (2010). A Review of the Literature on Light Flicker : Ergonomics, Biological Attributes, Potential Health Effects, and Methods in Which Some LED Lighting May Introduce Flicker. IEEE Standard, P1789 (December 2008), 1-26. Retrieved from http://grouper.ieee.org/ groups/1789/FlickerTR1_2_26_10.pdf

[42] Boisson, L. A., Kitsinelis, S., Zissis, G., Salon, J., Martin, S., \& Ouahhabi, N. (2013). Visual Perception of LED Flickering Controlled in a Colored Environment, 37(4), 183-188.
[43] Veitch, J. A. (2010). Light Source Flicker: When And How Does It Affect Us. DoE Market Introduction Workshop July 22, 2010 Source, 1-12.

[44] Daneault, V., Hébert, M., Albouy, G., Doyon, J., Dumont, M., Carrier, J., \& Vandewalle, G. (2014). Aging reduces the stimulating effect of blue light on cognitive brain functions. Sleep, 37(1), 85-96. http://doi.org/10.5665/sleep.3314

[45] Vandewalle, G., Balteau, E., Phillips, C., Degueldre, C., Moreau, V., Sterpenich, V., Maquet, P. (2006). Daytime Light Exposure Dynamically Enhances Brain Responses. Current Biology, 16(16), 1616-1621. http://doi.org/10.1016/j.cub.2006.06.031

[46] Cabeza, R., Daselaar, S. M., Dolcos, F., Prince, S. E., Budde, M., \& Nyberg, L. (2004). Task-independent and Task-specific Age Effects on Brain Activity during Working Memory, Visual Attention and Episodic Retrieval. Cerebral Cortex, 14(4), 364-375. http://doi.org/10.1093/cercor/bhg133

[47] Matsumoto, M. et al., (1998). Mersenne twister: a 623-dimensionally equi-distributed uniform pseudo-random number generator. ACM Transactions on Modeling and Computer Simulation 8(1): 3-30. doi:10.1145/272991.272995.

[48] Cohen, J. (1988). Statistical Power Analysis for the Behavioral, Sciences. 2nd ed. Hillsdale, NJ: Lawrence Erlbaum; 567 p.

[49] Hopkins, W. G. (2008). Research designs: Choosing and fine-tuning a design for your study. Sportscience, 12, 12-21. Retrieved from http://search.ebscohost.com/login.aspx?direct=true $\& d b=s 3 h \&$ $A N=36005990 \&$ lang $=$ cs $\&$ site $=$ ehost -live

[50] Girden, E.R., (1992). ANOVA: Repeated Measures, Newbury Park, CA: Sage University Press Series on Quantitative Applications in the Social Sciences, 07-084, ISBN: 9780803942578

[51] Iverson, G. R. and Norpoth, H., (1986), Analysis of Variance, 2nd ed. Newbury Park, CA: Sage University Press Series on Quantitative Applications in the Social Sciences, 07-001

[52] Higuchi, S., Ishibashi, K., Aritake, S., Enomoto, M., Hida, A., Tamura, M., Mishima, K. (2008). Inter-individual difference in pupil size correlates to suppression of melatonin by exposure to light. Neuroscience Letters, 440(1), 23-26. http://doi.org/10.1016/i.neulet.2008.05.037

[53] de Kort, Y., \& Smolders, K. (2010). Effects of dynamic lighting on office workers: First results of a field study with monthly alternating settings. Lighting Research and Technology, 42, 345360. http://doi.org/10.1177/1477153510378150

[54] Figueiro, M. M., Nonaka, S., \& Rea, M. S. M. (2014). Daylight exposure has a positive carry-over effect on nighttime performance and subjective sleepiness. Lighting Research \& Technology, 46(5), 506-519. http://doi.org/10.1177/1477153513494956

[55] Begemann, S. H. A., van den Beld, G. J., \& Tenner, A. D. (1997). Daylight, artificial light and people in an office environment, overview of visual and biological responses. International Journal of Industrial Ergonomics. http://doi.org/10.1016/S0169-8141(96)00053-4

[56] Privitera CM, Renninger LW, Carney T, Klein S, Aguilar M. The pupil dilation response to visual detection. Hum Vis Electron Imaging XIII. 2008;6806:68060T-1-68060T-11. 